Article

\title{
Large-Scale Virtual Screening Against the MET Kinase Domain Identifies a New Putative Inhibitor Type
}

\author{
Emmanuel Bresso ${ }^{1,+}{ }^{\oplus}$, Alessandro Furlan ${ }^{2,3,+}{ }^{\mathbb{C}}$, Philippe Noel $^{1}$, Vincent Leroux ${ }^{1}{ }^{\mathbb{D}}$, \\ Flavio Maina ${ }^{2}\left(\mathbb{D}\right.$, Rosanna Dono ${ }^{2}$ and Bernard Maigret ${ }^{1, *(\mathbb{D}}$ \\ 1 Université de Lorraine, CNRS, Inria, LORIA, F-54000 Nancy, France; emmanuel.bresso@loria.fr (E.B.); \\ philippe.noel@inria.fr (P.N.); vincent.leroux@gmx.com (V.L.) \\ 2 Aix Marseille Univ, CNRS, Developmental Biology Institute of Marseille (IBDM), UMR7288, \\ Parc Scientifique de Luminy, 13009 Marseille, France; alessandro.furlan@univ-lille.fr (A.F.); \\ flavio.maina@univ-amu.fr (F.M.); rosanna.dono@univ-amu.fr (R.D.) \\ 3 University of Lille, CNRS, UMR 8523, PhLAM-Physique des Lasers Atomes et Molécules, \\ F-59000 Lille, France \\ * Correspondence: bernard.maigret@loria.fr \\ + These authors contributed equally to this work.
}

Received: 27 January 2020; Accepted: 14 February 2020; Published: 19 February 2020

\begin{abstract}
By using an ensemble-docking strategy, we undertook a large-scale virtual screening campaign in order to identify new putative hits against the MET kinase target. Following a large molecular dynamics sampling of its conformational space, a set of 45 conformers of the kinase was retained as docking targets to take into account the flexibility of the binding site moieties. Our screening funnel started from about 80,000 chemical compounds to be tested in silico for their potential affinities towards the kinase binding site. The top 100 molecules selected-thanks to the molecular docking results-were further analyzed for their interactions, and 25 of the most promising ligands were tested for their ability to inhibit MET activity in cells. F0514-4011 compound was the most efficient and impaired this scattering response to HGF (Hepatocyte Growth Factor) with an $\mathrm{IC}_{50}$ of $7.2 \mu \mathrm{M}$. Interestingly, careful docking analysis of this molecule with MET suggests a possible conformation halfway between classical type-I and type-II MET inhibitors, with an additional region of interaction. This compound could therefore be an innovative seed to be repositioned from its initial antiviral purpose towards the field of MET inhibitors. Altogether, these results validate our ensemble docking strategy as a cost-effective functional method for drug development.
\end{abstract}

Keywords: virtual screening; ensemble-docking; structure-based drug design; cross-docking validation; induced fit; conformational selection; MET kinase

\section{Introduction}

MET receptor is a multifunctional receptor tyrosine kinase that plays a pivotal role in human development and tumorigenesis. Upon binding of its ligand HGF (Hepatocyte Growth Factor), MET triggers several intracellular signaling cascades, including MAPK and PI3K pathways, leading to various cellular responses, such as survival, proliferation, and migration, among others. MET activation can be driven in cancer by several mechanisms: HGF or MET overexpression, and also mutations [1].

Aberrant activation of MET signaling does not only affect cancer development and progression, but it also contributes to resistance against other cancer drugs [2-11]. Consequently, MET represents a pharmaceutically relevant target in anticancer drug design and has been the focus of several anticancer strategies [12-18]. Pioneer MET inhibitors such as SU11274, PHA665752, or AM7 were helpful for 
demonstrating the efficacy of MET inhibition to impair tumor growth in preclinical models. Then, further developments in the field led to the approval by the FDA of crizotinib and cabozantinib in the 2010s for treating non-small cell lung cancers and medullary thyroid cancers, respectively.

Even though promising results have been reported, the therapeutic activity of these drugs is still relative and efforts are required to identify new MET inhibitors with physicochemical properties optimized for clinical efficiency $[19,20]$. Moreover, new alterations in MET sequence have been recently identified, such as MET exon 14 skipping in lung cancers and the emergence of MET mutations in the kinase domain following treatment with MET inhibitors [21]. Novel inhibitor structures may possibly target these mutations with increased efficiency.

Designing new putative hits against MET therefore remains a valuable challenge to be tackled. In the present work, we carried out a virtual screening campaign in order to identify innovative compounds able to become new hits for further lead development. As MET plasticity upon ligand binding had been previously highlighted [22,23], we took into account this aspect for the molecular docking simulations. Indeed, MET can accommodate several distinct ligand binding modes and associated receptor conformations, a feature that is particular to the kinase family [24]. We reasoned that it should be taken into account for designing drugs with improved efficiency and selectivity profiles $[25,26]$. To be efficient, the molecular docking engines embedded within the virtual screening approaches must be adapted to handle such flexibility [27,28]. In the present work, we used the ensemble-docking strategy—previously recognized for its efficiency in drug design [29]—and show the benefit of an investigation using a large ensemble-docking on MET.

In previous medicinal chemistry works, we already identified novel MET inhibitors [30,31] and characterized the different MET ligand binding modes as shown by the stream of released X-ray data [32]. Here, we provide the results of a large-scale ensemble-docking investigation on MET, in which MET conformations are extended from available X-ray data to molecular dynamics and normal mode analysis. A limited number of candidate compounds were selected from the ensemble-docking results and one of them was subsequently validated experimentally as a possible new MET inhibitor, providing a valuable seed for further investigations.

\section{Materials and Methods}

\subsection{Screened Chemical Libraries}

The choice of an appropriated set of compounds to explore the virtual screening space is critical for assuming a good rate of success [33]. Today, millions of compounds can be selected for high-throughput screening, and a suitable selection strategy must be designed. In our case and according to previous success stories [34-36], we chose to use a set of libraries selected in order:

1. To use the highest possible chemical diversity, in order to cover a large spectrum of chemical structures [37-40];

2. To include kinase-targeted compounds, as such a choice is already proven to be successful [41,42];

3. To explore natural products, which are a promising source of anticancer drugs [43-45];

4. To take into account the repositioning of approved compounds, as drug repurposing presents an increasing interest in cancer research, by removing many costs associated with several steps of drug development [46-49]. Several proofs of concept are now available and a typical case of viral-to-cancer drug repositioning is gemcitabine with US patent No 4,808,614, aimed at treating viral infections, and the later-issued US No 5,464,826, which claims of its use to treat cancer. Therefore, we also considered chemical libraries dedicated to antiviral compounds.

According to the criteria listed above concerning the choice of the chemical libraries, we firstly downloaded around 200,000 compounds from the chemical providers listed in Table 1 . After eliminating redundancies in compounds and in scaffolds to assume a large chemical diversity and in respect of general druglike definitions [50], we finally retained about 80,000 compounds for our screening campaign. 
Table 1. List of the selected chemical libraries used in the present virtual screening campaign, providing a total of 76,251 compounds.

\begin{tabular}{ll}
\hline Supplier & Library Names \\
\hline French laboratories chimiotheque-nationale.enscm.fr & Selected subsets (kinase, essential, etc.) \\
Collaboration medchem.u-strasbg.fr & laboratory collection \\
ChemBridge www.chembridge.com & kinase library diversity library \\
kinase general library antiviral library & 15K diversity library \\
Life Chemicals www.lifechemicals.com & NDL + NPL natural derivatives library \\
TimTec www.timtec.net & all kinase library \\
& 10K diversity library \\
Otava otavachemicals.com & natural productlike library \\
& antivirus library natural compounds library \\
\hline
\end{tabular}

\subsection{Selected MET Conformational Ensemble}

In ensemble-based docking calculations, a well-suited choice of the protein target conformational sample is required to reproduce the protein plasticity and the possible induced-fit phenomena [51,52].

Concerning MET conformational flexibility, our previous exploration by molecular dynamics and normal mode simulations [22] was limited to the 26 PDB structures available at that time (Table 2). We have now extended this analysis by considering all the X-ray structures available for the wild-type MET in the PDB [53] deposited after 2012. From the additional structures found, only 19 were considered in this work (Table 3) as we discarded those where three regions were missing in the X-ray structure and those where the number of missing residues in a single region was larger than 20 . This selection aimed to improve our protein ensemble sample by covering most of the kinase structural characteristics, such as the position of the c-helix (in or out) or of the aspartate-phenylalanine-glycine (DFG) motif (in or out) as defined in Kinametrix [54], thus covering most of the inhibitor type binding modes. 3D structures considered in this ensemble of 45 conformers looked representative of the diversity of MET structures, as shown from the dendrogram, the heat maps, and correspondence maps in Figure 1. These results obtained thanks to the Dali server [55] clearly illustrate how MET 3D structures used here are organized into several families covering most of the protein conformational space presently known. 
Table 2. List of the 26 PDB MET kinase domain structures selected in the previous work [22] and reused in the present one. The kinase conformation associated to each structure is annotated according to the KinaMetrix web resource [56]: DO means DFG-out, DI means DFG-in, CO means $\alpha$-cHelix-out, CI means $\alpha$-cHelix-in, and $\omega$ CD indicates DFG intermediate.

\begin{tabular}{ccccc}
\hline $\mathbf{N}^{\boldsymbol{o}}$ & PDB ID & Ligand PDB ID & Deposition Date & Annotation \\
\hline 1 & 1R0P & KSA & 2003 & Inactive CODI \\
2 & 2RFN & AM7 & 2007 & $?$ \\
3 & 2RFS & AM8 & 2007 & Inactive CODI \\
4 & 3C1X & CKK & 2008 & Inactive CIDO \\
5 & 3CCN & LKG & 2008 & Inactive CODI \\
6 & 3CD8 & L5G & 2008 & Inactive CODI \\
7 & 3CE3 & 1FN & 2008 & Inactive CODO \\
8 & 3CTH & 319 & 2008 & Inactive CIDO \\
9 & 3CTJ & 320 & 2008 & Inactive CIDO \\
10 & 3F66 & IHX & 2008 & Inactive CODI \\
11 & 3F82 & 353 & 2008 & Inactive CIDO \\
12 & 3EFJ & MT3 & 2008 & Inactive CODO \\
13 & 3EFK & MT4 & 2008 & Inactive CODI \\
14 & 2WD1 & ZZY & 2009 & Inactive CODI \\
15 & 3DKC & ATP & 2009 & Inactive CODI \\
16 & 3DKF & SX8 & 2009 & Inactive CODI \\
17 & 2WGJ & VGH & 2009 & Active CIDI \\
18 & 3A4P & DFQ & 2010 & Inactive CODI \\
19 & 3L8V & L8V & 2010 & Inactive CIDO \\
20 & 3I5N & B2D & 2010 & Inactive CODI \\
21 & 3LQ8 & $88 Z$ & 2010 & Inactive CODO \\
22 & $2 W K M$ & PFY & 2010 & Inactive CODI \\
23 & 3Q6W & Q6W & 2011 & Active CIDI \\
24 & 3QTI & 3QT & 2011 & Inactive CODI \\
25 & 3RHK & M97 & 2011 & Inactive 6 CD \\
26 & 3ZXZ & KRW & 2011 & Inactive CODI \\
\hline & & & &
\end{tabular}

Table 3. List of the PDB MET kinase domain structures added to the ones coming from our previous work [22]. The kinase conformation associated to each structure is annotated according to the KinaMetrix web resource [56]: DO means DFG-out, DI means DFG-in, CO means $\alpha$-cHelix-out, CI means $\alpha$-cHelix-in, and $\omega \mathrm{CD}$ indicates DFG intermediate.

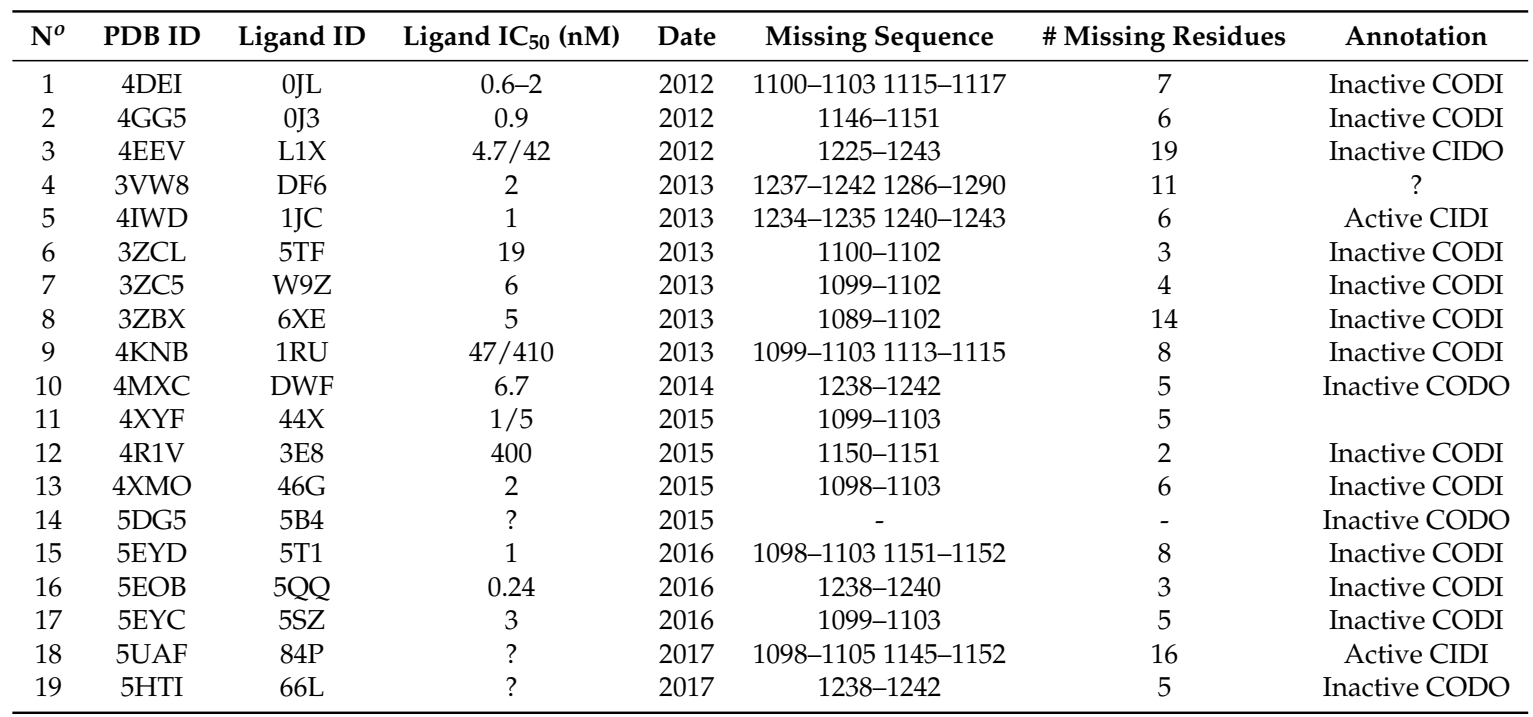

To be in accordance with the 26 conformers coming from our previous work [22], the 19 added crystal structures were prepared and cleaned following the same protocol: missing residues, side 
chains, and hydrogens were added when necessary; unnecessary water molecules, ions, and additives were removed; basic and acidic side chains were ionized according to a $\mathrm{pH}$ set to 7 . To consider possible binding sites fluctuations, short molecular dynamics (MD) simulations were undertaken for each of these 19 structures. For that purpose, these structures were placed in a solvent box of $80 \AA$ and counter ions were added for electrostatic neutrality. NAMD [57] molecular dynamics program was used with the same CHARMM36 force field and same protocol as previously described [22]. After minimization and equilibrium steps (64,000 conjugate gradients and $1 \mathrm{~ns} \mathrm{MD}$, respectively), $10 \mathrm{~ns}$ of MD were recorded, with a frame length of 1 ps. These $19 \mathrm{MD}$ trajectories were analyzed, and the most stable representative conformer was retained for each of them and added in the ensemble-docking set.

(a)

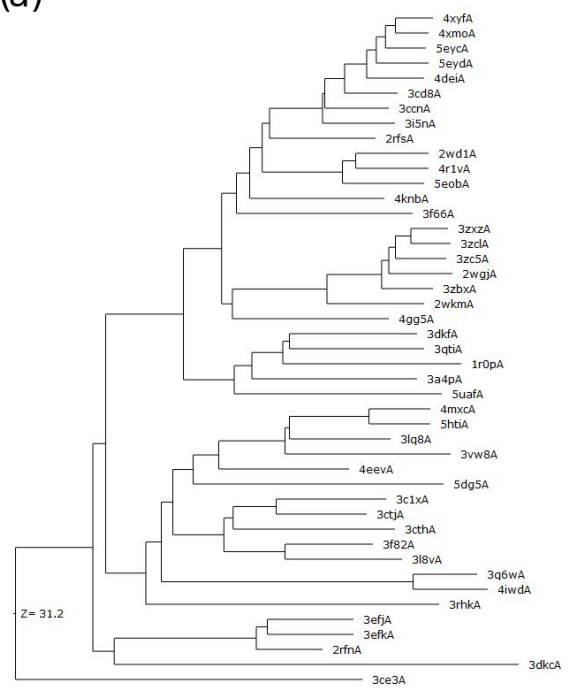

(b)

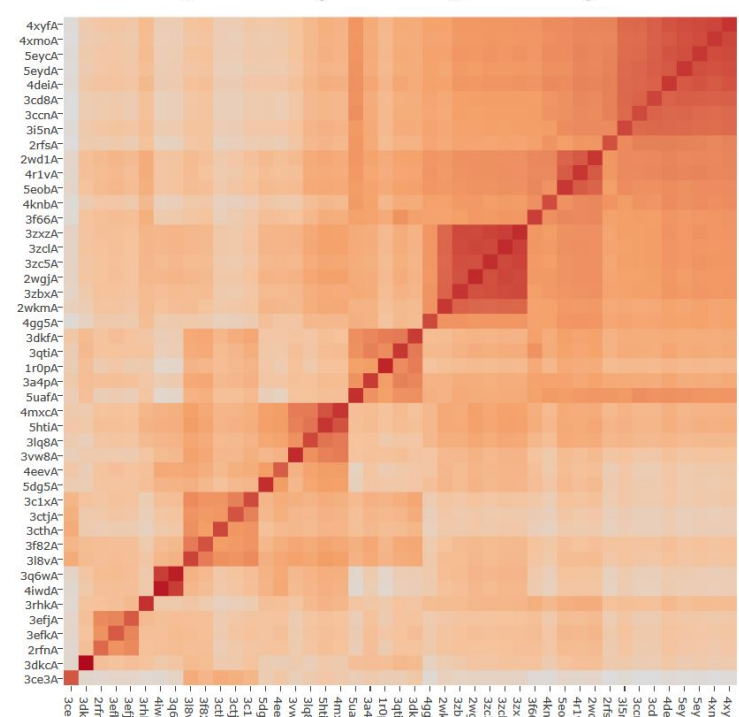

(C) Correspondence analysis

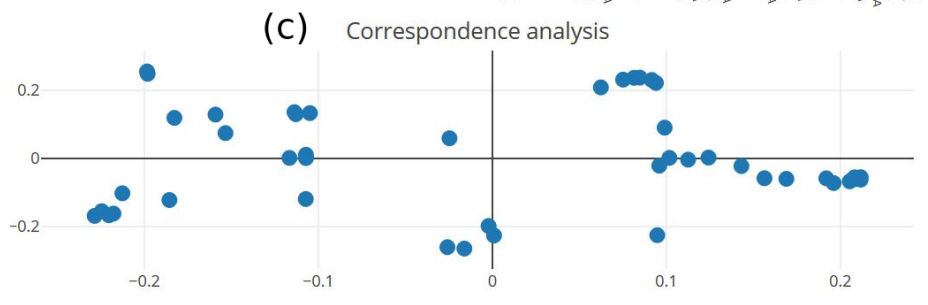

Figure 1. (a) Dendrogram showing the relationships between the 45 PDB conformers listed in Tables 2 and 3 and used to sample MET structure plasticity. (b) Similarity heat-map showing the relationships between the 45 PDB conformers and used to sample MET structure plasticity. The color scale corresponds to the Dali Z-score values. (c) Correspondence analysis of the 45 ensemble PDB-related conformers. This plot positions data points with the most similar structural neighborhoods near each other according to a multidimensional scaling method.

\subsection{Description of the Ensemble-Docking Protocol}

The ensemble-docking facility proposed in the GOLD docking program was used [58]. This GOLD feature evaluates different receptor conformations concurrently during the docking exploration. The protein ensemble used in this work thus contained 45 MET conformers (26 from our previous work and 19 added in this one). As these conformers must be superimposed before being used in GOLD ensemble-docking program, they were structurally aligned according to their conserved and most rigid secondary structure patterns, as previously described [22] and summarized in Table 4. 
Table 4. List of the secondary structure elements used for aligning all the conformers.

\begin{tabular}{lll}
\hline Domain & Secondary Structure Name & Residues \\
\hline N-terminal & $\beta 1$ & 1076 to 1081 \\
& $\beta 2$ & 1092 to 1098 \\
& $\beta 2$ & 1104 to 1110 \\
& $\beta 2$ & 1144 to 1146 \\
& $\beta 2$ & 1154 to 1158 \\
C-terminal & $\alpha \mathrm{E}$ & 1178 to 1198 \\
& $\alpha \mathrm{F}$ & 1263 to 1278 \\
& $\alpha \mathrm{H}$ & 1310 to 1320 \\
& $\alpha \mathrm{I}$ & 1330 to 1343 \\
\hline
\end{tabular}

When docking an ensemble of conformations for a given protein, their binding sites must be defined using a method that is not conformer specific. In the present ensemble-GOLD version, as it was not possible to define the active site by a list of atoms or residues, the only way was to use the centroid of the binding cavity and a sphere radius around this point. Therefore, for each of the 45 aligned protein conformers used here, protein cavities and their center of mass were detected by the LIGSITE program [59]. From these data, we obtained an average center point as the ensemble binding site definition for GOLD. Figure 2 presents the position of this average center point within the 45 protein conformers. A radius of $20 \AA$ was associated to this average point to define the binding cavity of each conformer in order to correctly encompass the receptor for all the conformations in the ensemble, including conformational variations around the center. We also verified that the resulting sphere was encompassing all groups of residues previously identified as potential interaction areas for MET ligands [32].

For each docking run, we used 50 starting poses/molecule for the GOLD generic algorithm. Tested compounds were ranked by the standard goldscore scoring function.

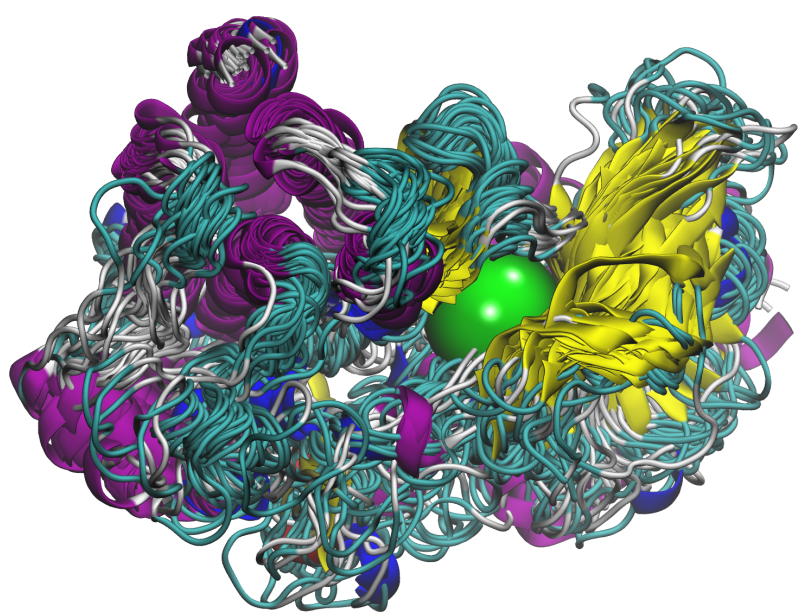

Figure 2. Position of the average center-point (as a green sphere) found from the 45 used conformers and used for the ensemble-dockings.

\subsection{Computer Grid Facilities}

Due to the massive calculations needed ( 80,000 molecules $\times 48$ protein ensemble conformers $\times 50$ poses/molecule), and considering the computing time to achieve only one run, we used the Grid5000 facility [60] providing the required computer power in order to distribute the calculations using the PVM framework embedded in GOLD. A total of 1300 cpus (mostly Xeons) with 4 GB $\mathrm{RAM} /$ core and infiniband connections were used for each run. The docking performances run around 300-docked ligands/ensemble/hour. The calculations were spread on the clusters using the same strategy as previously described [61]. 


\subsection{Scattering Assays}

The experimental protocols for measuring the potency of MET inhibitors are detailed in previous publications [30,62]. MDCK cells were preincubated with compounds overnight at 0.1-100 $\mu \mathrm{M}$ concentrations at $37^{\circ} \mathrm{C}$ in a humidified atmosphere of $5 \% \mathrm{CO}_{2}$, followed by a $24 \mathrm{~h}$ stimulation with $20 \mathrm{ng} / \mathrm{mL} \mathrm{HGF}$ (R\&D Systems). Cells were further incubated at $37^{\circ} \mathrm{C}$ in an atmosphere of $5 \% \mathrm{CO}_{2}$ for $24-48 \mathrm{~h}$, washed with phosphate buffered saline (PBS; Gibco BRL), and fixed with $4 \%$ PFA (paraformaldehyde, Sigma). The quantification of scattering response was performed by counting the number of cells with scattered morphology in 30 independent colonies. The $\mathrm{IC}_{50}$ corresponds to the concentration of compounds leading to a $50 \%$ inhibition of MET-triggered cell scattering.

\section{Results}

\subsection{Preliminary Validation Concerning the GOLD Ensemble-Docking Protocol Used}

The coordinates of the 45 aligned conformers and of the sphere representing their common binding sites constituted our ensemble-docking protein reference.

The first question here concerned the accuracy of this binding site definition compared to ones that are more classical. For that, we compared the docking results for some of the selected $45 \mathrm{MET}$ conformers using three binding site definitions; namely, a residue list, an existing ligand, and the center point of the binding cavity, respectively. For each individual docking target, the three definitions provided almost the same rank and docking score for the associated PDB ligand (Table 5). Moreover, the poses of this ligand found using the three binding site definitions were similar to the pose found in the crystal structures, as illustrated with the example of the AM7 ligand on Figure 3.

Table 5. Comparison of the docking results using the 3 binding site definitions.

\begin{tabular}{ccccc}
\hline Definition of the Binding Site & Target PDB Name & Ligand PDB Name & Rank Number & Score Value \\
\hline \multirow{2}{*}{ Center + radius 20 A } & 3DKC & ATP & 1 & 105.5 \\
& 2RFN & AM7 & 1 & 100.8 \\
Residues list & 3DKC & ATP & 1 & 102.8 \\
\multirow{2}{*}{ From its PDB ligand } & 2RFN & AM7 & 1 & 98.0 \\
& 2RFC & ATP & 1 & 107.1 \\
\hline
\end{tabular}

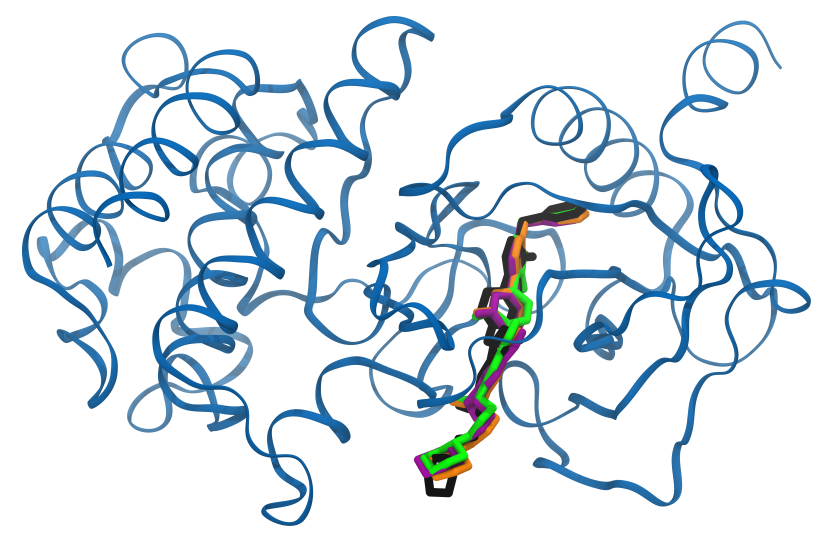

Figure 3. Poses of the AM7 ligand in the X-ray 2 RFN structure compared to the docking results. In black, the original pose of the ligand in its PDB protein conformation; in colors, the best docking poses obtained by GOLD on the 2RFN target using a definition of the binding site from a list of residues (orange), from the original ligand (green), and from a center-point (purple).

The second question was related to the ability of the ensemble-docking process to retrieve a given PDB ligand to its PDB structure among the 45 ones. To evaluate that point, an ensemble-docking calculation was carried out on the 45 protein target conformers using a short chemical library built 
from their own 45 associated ligands (the list is given in Tables 2 and 3). We checked whether we could associate the right PDB target for a given PDB ligand (with possibly similar rank, score and pose compared to the ones found for the individual target dockings) in the protein ensemble. This was achieved for almost $80 \%$ of the compounds (Table S1). For example, the KSA ligand was able to preferentially retrieve its original 1ROP partner among the ensemble of the 45 PDB conformers of the protein target.

From these results, it appeared that the ensemble-docking procedure we used was a satisfactory method to tackle multiple conformers docking and to achieve a valuable virtual screening.

\subsection{Selection of Candidate Hits from the Virtual Screening Campaign}

Once the screening campaign was achieved for the 80,000 compounds filtered from the chosen libraries, we kept the top-100 ranked compounds according to their GOLD scores (ranging from 100 to 114) for further analysis.

We started the docking analysis with the Life Chemicals compound F0725-0356 giving the best docking score of 114. A comparison between the X-ray complex 3EFK/MT4 structure and the MD_3EFK/F025-0356 one presented quite similar poses and protein/ligand interactions. Indeed, the most important residues known in MET interactions (namely, $\operatorname{Met}_{1160}, \mathrm{Asp}_{1222}, \mathrm{Tyr}_{1159}$ ) were found in both complexes.

We next analyzed the protein-ligand interactions for the other top-100 compounds in order to compare them to the ones found in the 45 original PDB structures (Tables 2 and 3). For that, we used the PLIP program [63] by focusing on two important interaction types: hydrogen bonds and $\pi$-stacking. Protein residues $\operatorname{Met}_{1160}(45 / 45), \operatorname{Asp}_{1222}(34 / 45)$, and Lys $1110(6 / 45)$ concentrated the vast majority of hydrogen bonds with ligands; while $\operatorname{Tyr}_{1230}(25 / 45)$ and $\mathrm{Phe}_{1223}(7 / 45)$ dealt with most of the $\pi$-stacking. In order to limit our biological tests on possible promising compounds, we eliminated from the top-100 list the molecules not presenting at least one hydrogen bond and one $\pi$-stacking from the ones described above in the PDB complexes.

After this filter, we retained only 41 compounds as satisfying these criteria. As most of these compounds came from the Life Chemical antiviral library and given the simplicity of comparing molecules from the same supplier, we decided to only test compounds from Life Chemicals. As some of these molecules were not available in stock from this provider, only the 25 compounds listed in Table 6 were finally kept to proceed further. 
Table 6. Ligands selected from the Life Chemical (LC) antiviral library and experimentally tested. "-": the compound (assessed at a concentration up to $100 \mu \mathrm{M}$ ) did not affect MDCK cell scattering in response to HGF/SF. "+": the compound impaired MDCK cell scattering in response to HGF/SF with an $\mathrm{IC}_{50}>10 \mu \mathrm{M}$. "+++": the compound impaired MDCK cell scattering in response to HGF/SF with an $\mathrm{IC}_{50}<10 \mu \mathrm{M}$.

\begin{tabular}{|c|c|c|c|c|}
\hline Mol ID & Life Chemicals Name & GOLD Score & Best Protein Conformer & Biological Activity \\
\hline 1 & F0725-0356 & 120.7 & MD_3EFK & - \\
\hline 2 & F0772-0607 & 111.8 & MD_3EFK & - \\
\hline 3 & F0816-0342 & 111.2 & MD_3F82 & - \\
\hline 4 & F0737-0405 & 110.6 & MD_3EFJ & - \\
\hline 5 & F0737-0393 & 110.1 & MD_3EFK & - \\
\hline 6 & F0301-0263 & 105.5 & MD_3EFK & - \\
\hline 7 & F0721-0868 & 105.1 & MD_3EFK & - \\
\hline 8 & F0715-0299 & 105.0 & MD_3EFK & - \\
\hline 9 & F0539-1482 & 104.0 & MD_3EFJ & + \\
\hline 10 & F0385-0029 & 103.8 & MD_3EFK & - \\
\hline 11 & F0385-0334 & 103.4 & MD_3EFJ & - \\
\hline 12 & F0514-4011 & 103.3 & MD_3EFJ & +++ \\
\hline 13 & F0174-0048 & 102.4 & MD_3EFK & - \\
\hline 14 & F1620-0074 & 102.1 & MD_3EFJ & - \\
\hline 15 & F0011-0324 & 102.0 & MD_3EFK & - \\
\hline 16 & F0721-0906 & 102.0 & MD_3EFJ & - \\
\hline 17 & F0012-0227 & 101.9 & MD_3EFJ & - \\
\hline 18 & F0721-0911 & 101.9 & MD_3EFJ & - \\
\hline 19 & F0715-0300 & 101.8 & MD_2RFN & - \\
\hline 20 & F2252-0240 & 101.1 & MD_3EFK & - \\
\hline 21 & F0772-2099 & 100.9 & MD_3EFJ & - \\
\hline 22 & F0473-0261 & 100.9 & MD_3CE3 & - \\
\hline 23 & F0721-0900 & 100.5 & MD_3EFK & - \\
\hline 24 & F0772-2147 & 100.5 & MD_3EFJ & - \\
\hline 25 & F0526-0094 & 100.3 & MD_3EFJ & - \\
\hline
\end{tabular}

\subsection{F0539-1482 and F0514-4011 Inhibit MET-Induced Cell Scattering}

These 25 compounds were then experimentally tested for their ability to restrain MET-triggered biological activities. We previously efficiently screened compounds for their inhibitory properties towards MET-triggered biological responses by using cell scattering assays [31,64]. In particular, MDCK epithelial cells acquire a "scattered phenotype" after stimulation with MET ligand HGF.

Among the 25 tested compounds, two compounds were found active, namely, F0539-1482 and F0514-4011. F0514-4011 was the most efficient and impaired this scattering response to HGF with an $\mathrm{IC}_{50}$ of $7.2 \mu \mathrm{M}$ (Figure 4). No toxic effects were observed at biologically active concentrations. This study thus demonstrates that our strategy actually allows the identification of compounds able to inhibit MET-driven biological activities. 
(a)

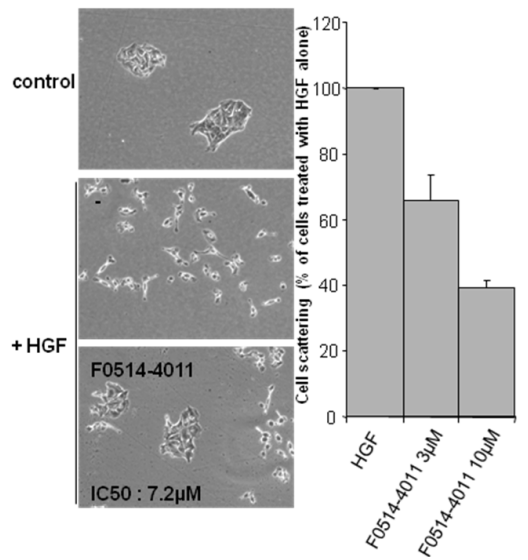

(b)

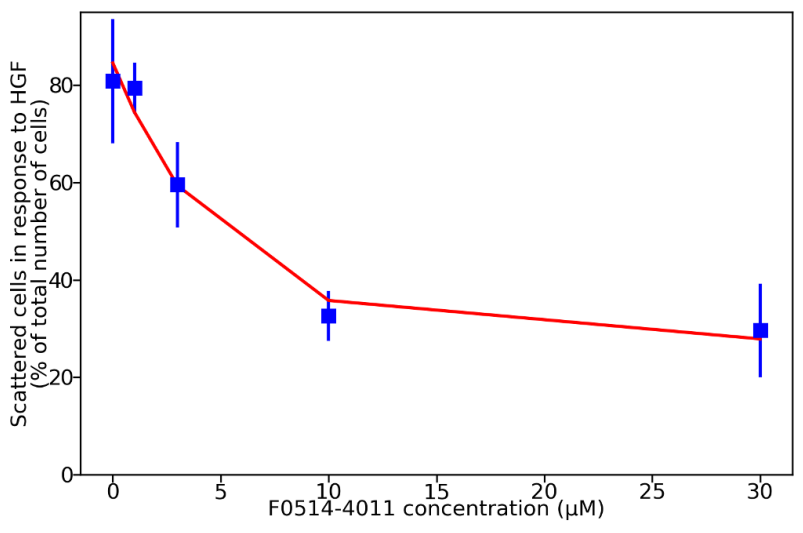

Figure 4. (a) F0514-4011 impairs cell scattering in response to MET ligand HGF: MDCK epithelial cells were treated with $20 \mathrm{ng} / \mathrm{mL}$ HGF, with or without preincubation with F0514-4011 for $2 \mathrm{~h}$. F0514-4011 $\mathrm{IC}_{50}$ is $7.2 \mu \mathrm{M}$. (b) Dose-response curve for F0514-4011.

\subsection{Compared Docking of F0514-4011 Compound Versus Known Inhibitors}

In order to understand why the compound F0514-4011 (Figure 5) was the most potent compound among the 25 experimentally tested ones while not presenting the highest GOLD score, we compared its docking data with those of potent existing inhibitors. For that, we collected the structures of ligands found in the PDB related to MET kinase domain in complex with already marketed inhibitors with binding $\mathrm{IC}_{50}$ found in the $\mathrm{nM}$ range (Table 7). All these compounds were submitted to the ensemble-docking GOLD protocol already used for our virtual screening campaign. From these calculations, it appeared that the best docking scores ranged from 111 for merestinib (L1X ID in PDB 4EEV) to 83 for AMG337 (5T1 ID in PDB 5EYD), so that the score of 103 obtained for our active F0514-4011 compound was in this range of active compounds. Considering now $\mathrm{IC}_{50}$, one possibility to explain the higher $\mathrm{IC}_{50}$ of $7.2 \mu \mathrm{M}$ obtained for F0514-4011 (compared to 0.4-14 $\mu \mathrm{M}$ range found for compounds listed in Table 7) could be its weaker solubility (cLogP of 5.7, greater than that of all compounds listed in Table 7).

Table 7. Data used for some known marketed inhibitors with nano-molar range $\mathrm{IC}_{50}$ found in the PDB.

\begin{tabular}{cccccc}
\hline PDB ID & Ligand ID & Name & IC50 & Solubility cLogP & Docking Score \\
\hline 2RFS & AM8 & SU11274 & $10 \mathrm{nM}$ & 2.9 & 86 \\
2WGJ & VGH & Criotinib & $11 \mathrm{nM}$ & 3.5 & 82 \\
2WKM & PFY & PHA-665752 & $9 \mathrm{nM}$ & 4.4 & 88 \\
3DKF & SX8 & SGX-523 & $4 \mathrm{nM}$ & 1.4 & 84 \\
3RHK & M97 & Tivantinib & $4 \mathrm{nM}$ & 3.1 & 83 \\
3LQ8 & 88Z & Fortinib & $0.4 \mathrm{nM}$ & 4.3 & 99 \\
3Q6W & Q6W & MK-2461 & $0.4 \mathrm{nM}$ & 3.3 & 93 \\
3QTI & 3QT & NVP-BVU972 & $14 \mathrm{nM}$ & 1.6 & 84 \\
3ZXZ & KRW & PF-04217903 & $5 \mathrm{nM}$ & 0.2 & 87 \\
4EEV & L1X & Merestinib & $5 \mathrm{nM}$ & 3.4 & 111 \\
5EYD & 5T1 & AMG337 & $1 \mathrm{nM}$ & 0.3 & 83 \\
\hline
\end{tabular}




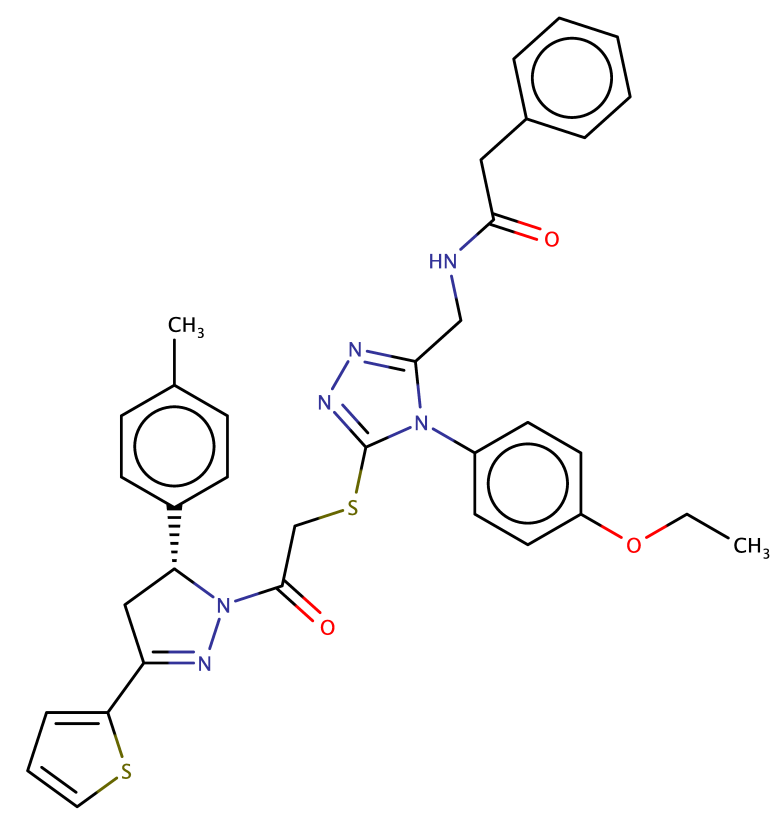

Figure 5. F0514-4011: N-[[4-(4-Ethoxyphenyl)-5-[2-[3-(4-methylphenyl)-5-thiophen-2-yl-3,4-dihydropyrazol -2-yl]-2-oxoethyl]sulfanyl-1,2,4-triazol-3-yl]methyl]-2-phenylacetamide.

Another point concerned the interaction of F0514-4011 with amino acid residues within the protein-binding region. In Table 8, we have listed the protein residues/ligand interactions found from Table 7 PDB complexes, as calculated by the PLIP program. These interactions were compared to the ones obtained for F0514-4011 from its best pose MD_3EFJ in the ensemble MET conformations. From this comparison, it appears that several of the most important amino acid residues found from the PDB protein/ligand analysis were also found for F0514-4011, at the exception of Met $_{1160}$, common to all PDB structures of Table 8, replaced possibly by Met $_{1131}$ and Met $_{1229}$ in our case. This situation is mostly due to the conformation of the large DFG loop acting as a highly flexible lid protecting the binding sites which was quite different in the MD_3EFJ conformation, found as the most suitable one to bind F0514-4011 when compared to the PDB ones (see Figure 6 for an example with the 5DG5 and $4 \mathrm{DEI}$ structures). Therefore, our docking results concerning the best pose proposed by GOLD for F0514-4011 appear quite in agreement with most of data obtained from all the PDB concerning MET kinase domain complexed with inhibitors. 
Table 8. List of the protein residues interacting with a nM. inhibitor from the PDB complexes of Table 7 ranked by their number of occurrence. In bold, the residues also found in the interactions with F0514-4011 with the MD-3EFJ MET conformation. According to the PLIP results, a residue was marked "+ " when at least one protein-ligand interaction was found, whatever its quality (hydrophobic, H-bond, $\pi$-stacking, ionic, etc.) and marked by "_“ when no protein-ligand interaction was found.

\begin{tabular}{|c|c|c|c|c|c|c|c|c|c|c|c|}
\hline \multirow[b]{2}{*}{ Residue } & \multicolumn{11}{|c|}{ PDB IDs } \\
\hline & 4EEV & 2WGJ & 5EYD & $3 Z X Z$ & 2RFS & 3RHK & 3QTI & 3Q6W & 2WKM & 3DKF & 3LQ8 \\
\hline $\mathrm{MET}_{1160}$ & + & + & + & + & + & + & + & + & + & + & + \\
\hline $\mathbf{L E U}_{1157}$ & + & + & + & - & + & + & + & + & + & + & + \\
\hline $\mathbf{A S P}_{1222}$ & + & - & + & + & + & - & + & - & - & + & + \\
\hline $\mathrm{ALA}_{1108}$ & + & - & + & + & - & - & + & + & - & + & + \\
\hline $\mathrm{TYR}_{1230}$ & - & + & + & + & + & - & + & - & + & + & - \\
\hline VAL $_{1092}$ & - & + & - & + & - & + & + & + & - & + & - \\
\hline ILE $_{1084}$ & + & + & + & + & & + & + & + & - & + & + \\
\hline TYR $_{1159}$ & - & - & - & - & - & - & - & + & + & - & + \\
\hline $\mathrm{PRO}_{1158}$ & - & + & - & - & + & + & - & - & + & - & - \\
\hline $\mathbf{L E U}_{1140}$ & - & - & - & - & + & - & - & + & + & - & + \\
\hline $\mathbf{A L A}_{1221}$ & - & - & - & - & - & - & + & + & - & + & - \\
\hline $\mathrm{PHE}_{1223}$ & + & - & - & - & - & + & - & - & - & - & + \\
\hline $\mathrm{ASP}_{1164}$ & - & - & - & - & - & - & - & - & + & + & - \\
\hline LYS $_{1110}$ & + & - & - & - & - & + & - & - & - & - & - \\
\hline $\mathrm{ASN}_{1209}$ & - & - & - & - & - & - & - & - & + & - & - \\
\hline $\mathrm{GLU}_{1127}$ & - & - & - & - & - & - & - & - & - & - & + \\
\hline PHE $_{1134}$ & + & - & - & - & - & - & - & - & - & - & + \\
\hline VAL $_{1139}$ & + & - & - & - & - & - & - & - & - & - & + \\
\hline $\mathrm{PHE}_{1200}$ & + & - & - & - & - & - & - & - & - & - & + \\
\hline $\mathrm{ARG}_{1086}$ & - & - & - & - & - & - & - & + & - & - & - \\
\hline $\mathrm{ARG}_{1208}$ & - & - & - & - & - & - & - & + & - & - & - \\
\hline $\mathrm{THR}_{1343}$ & - & - & - & - & - & - & + & - & - & - & - \\
\hline $\mathrm{GLU}_{1347}$ & - & - & - & - & - & - & + & - & - & - & - \\
\hline PHE $_{1089}$ & - & - & - & - & - & + & - & - & - & - & - \\
\hline $\mathrm{ASP}_{1231}$ & - & - & - & + & - & - & - & - & - & - & - \\
\hline $\mathrm{ARG}_{1166}$ & - & - & - & + & - & - & - & - & - & - & - \\
\hline $\mathrm{ASN}_{1167}$ & - & - & - & + & - & - & - & - & - & - & - \\
\hline ILE $_{1130}$ & + & - & - & - & - & - & - & - & - & - & - \\
\hline $\mathrm{ASN}_{1171}$ & - & - & - & - & - & - & - & - & - & - & - \\
\hline
\end{tabular}

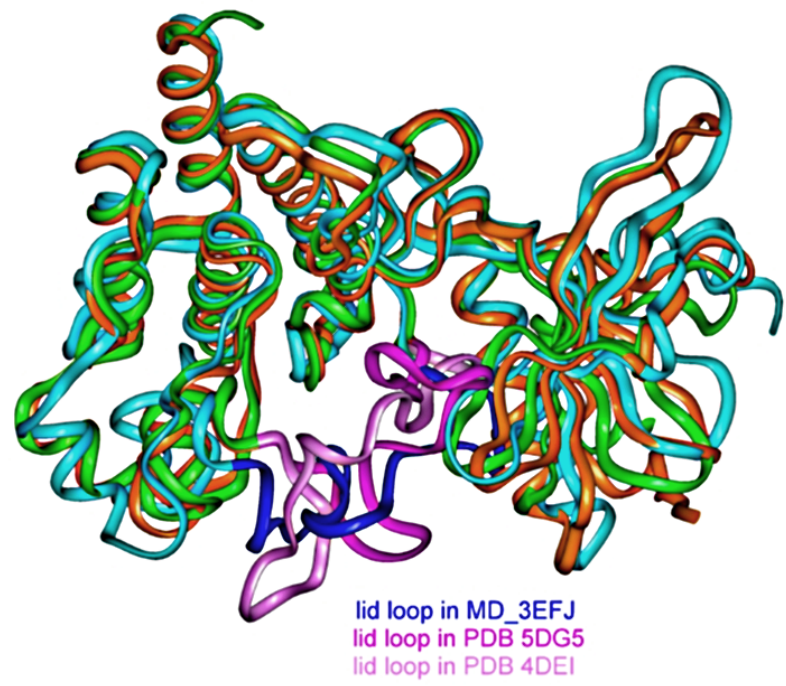

Figure 6. Differences for the lid DFG loop between selected PDB structures and our MD-refined MD_3EFJ conformations. The proteins are depicted from their $\mathrm{C}^{\alpha}$ ribbon-like traces.

To further characterize the F0514-4011 inhibitor type, we have considered the general 3D shape of known kinase inhibitors as analyzed in several papers [7,65-67]. Concerning MET, such compounds 
are generally classified as type-I or -II. Type-I ligands essentially bind at the ATP binding site and present a U-shaped conformation, with the protein in the DFG-in structure; while type II are found in an extended shape and correspond to the DFG-out protein form. We illustrate this in Figure 7, showing the conformations of two typical ligands, namely, type-I AMG337 (from PDB 5EYD) and the type-II altiratinin analog DP-4157 (from PDB 5DG5). From this picture, it appears that F0514-4011 presents both the $U$ and linear shapes while also showing another region of interaction, including three of the protein residues already found in MET complexes-namely, Asp ${ }_{1222}, \operatorname{Tyr}_{1230}$, and $\operatorname{Arg}_{1208}$ (found only 2 times for 3C1X and 3YW8 among our 45 ensemble conformations). Asp 1204 and Asn $_{1209}$ residues, still not involved in MET complex PDB structures, complement this supplementary binding pocket. The thiophene moiety of F0514-4001 was placed central within this pocket by the thiophene-pyrazole group which also oriented the associated toluene ring to close the U-shape part. Therefore, one could postulate that F0514-4011 molecule describes a possibly novel type of inhibitor.

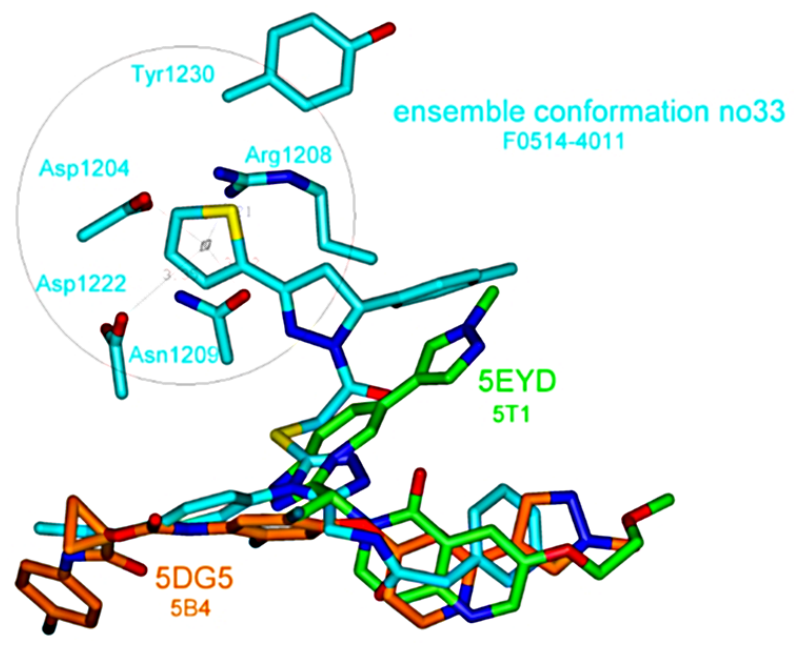

Figure 7. Comparison of the conformations between F0514-4011, the U-shape inhibitor 5T1 (AMG337), and the linear-shape 5B4 (altiratinib), as observed in their respective binding sites.

Nevertheless, considering the limitations of any docking program, the stability of F0514-4011's best docking pose could be questioned. In order to validate it, we have performed a molecular dynamics simulation using the same conditions as those used for the PDB complexes (cubic water box of $80 \AA^{3}$ ). The results show that the GOLD docking pose is very stable and still conserved after 10 ns of MD (Figure 8). The protein/ligand interactions found for F0514-4011 after the MD simulation were similar to those discussed above, thus giving confidence to the robustness of the docking results. Our final question concerns the originality of F0514-4011 compared to the known MET ligands. The Tanimoto similarity index calculated between F0514-4011 and most of the published MET ligands shows that the molecule identified by our virtual screening campaign seems to be an innovative hit as all the Tanimoto values are low, ranging from 0.39 (with the pioneer inhibitor PHA-665752) to 0.12 (for norcantharidin) (Table S2). We have completed this quite elementary similarity search by using the ChemDes web server [68], which allows a large panel of similarity fingerprint types as well as fingerprints descriptors and similarity measures. Using this web server, we mined several databases collecting MET known inhibitors (such as the PDB or PubChem [69]), already in clinical trials (such as MDDR [70]), or described as putative inhibitors (such as in Life Chemical or sellekchem [71] providers). The results obtained with this method confirmed the lack of similarity suggested with the Tanimoto distance. With the Sokal similarity method and DTRF fingerprint types, the similarities ranged from 0.46 to 0.19 (in the PDB list, a maximum of 0.40 was obtained for compound ID 75H found in PDB ID 5T3Q (data not shown)). This could be due to the thiophene moiety of F0514-4011, as we have found only two papers and one patent in the literature referring to thiophene-related MET inhibitors [72-74] and only one reference to the role of thiophene-pyrazole moiety in kinase inhibition [75]. 


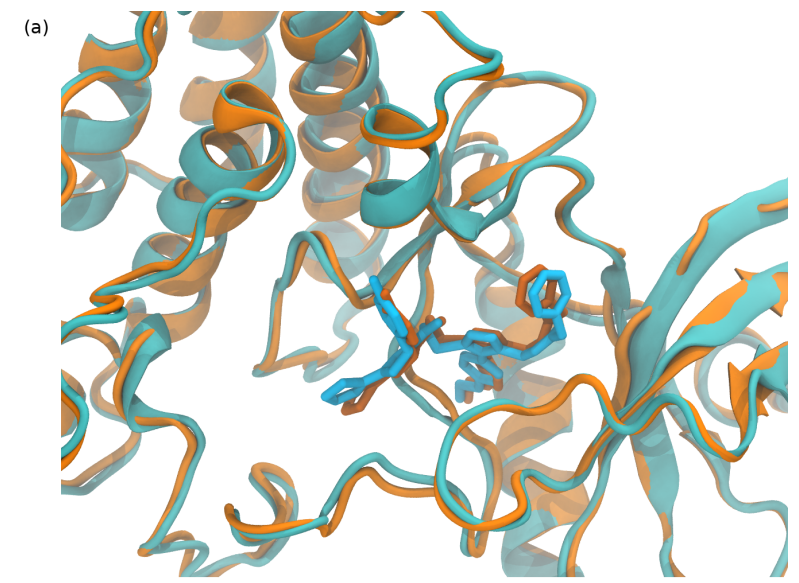

(b)

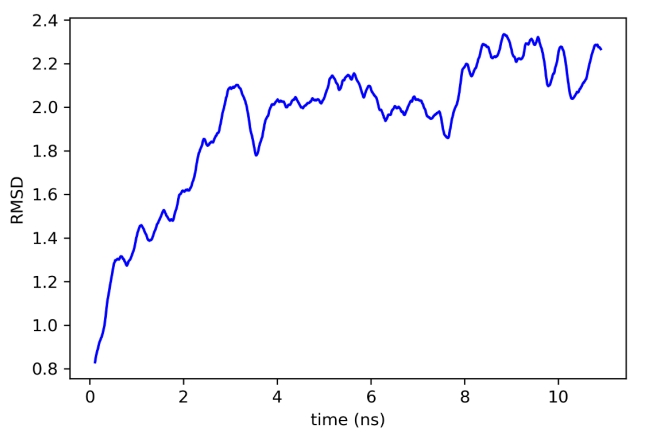

Figure 8. (a) Comparison between the initial docking pose (in orange) of F0514-4011 and the final one after the 10-ns MD simulation (in cyan). (b) Evolution of F0514-4011 root mean square deviation (RMSD) during $11 \mathrm{~ns}$ ( $1 \mathrm{~ns}$ equilibrium and $10 \mathrm{~ns}$ production) of MD simulation. Poses were aligned on the initial one and the curve was smoothed.

\section{Discussion}

Molecular docking, molecular dynamics, and virtual screening approaches can now be efficiently used for the design of new inhibitors of the MET kinase domain [27,56,76-80]. From all these approaches, new potent compounds were obtained and more highlights revealed about MET kinase domain conformational behavior. In this vein, our study merges both simulations and experiments and highlights a novel scaffold for MET inhibition.

Using an ensemble-docking approach associated to short molecular dynamics runs in order to take into account the flexibility of the used X-ray structures in the protein conformational ensemble, we were faced with the fundamental question of the relevance of this strategy for handling the difficult problem of predicting ligand-binding modes on a flexible target. This is especially true for MET kinase, the active site of which exhibits important structural variations, as observed in their available crystal structures $[81,82]$. We believe that this work brings a positive answer to this question and can constitute a working line for other simulations in the future. Ensemble-docking is now widely used, and incorporating this approach to short molecular dynamics simulations looks promising. Still, a couple of simple questions have to be answered prior to initiating the docking calculation: how do we generate a relevant ensemble for a given receptor [51], and how can we be sure that the possible energy differences obtained between conformations in the ensemble are properly accounted for?

Interestingly, F0514-4011 compound (also referenced in PubChem with ID 5237313) is not a newcomer in drug design as it has been already tested as a possible activator of E3 ligase (FBW7) and inhibitor of microphthalmia-associated transcription factor (MITF), but was found inactive in both assays . Our study suggests that it could be repositioned for MET inhibition, as evidenced by its biological activity against MET-driven cell scattering. Some drug properties such as solubility and lack of toxicity were already known. With regard to its molecular weight of $650 \mathrm{Da}$, which could be 
considered as limiting its possible therapeutic action, it should be noted that other inhibitors currently on the market have similar characteristics such as tarloxatinib (679Da), foretinib (632Da), or golvatinib (633Da). Therefore, it should not be a major hurdle if lead optimization provides us with a promising drug in terms of activity and/or selectivity. This will be the topic of future investigations.

This virtual screening work presents F0414-4011 as a valuable compound that could be a seed for developing new and innovative leads against MET kinase. Its novelty and originality might be used to overcome the resistance problem found presently for several existing inhibitors.

Supplementary Materials: The following are available online. Table S1: Comparison of the ensemble-docking results to the individual ones (a ligand against its own PDB-related structure), Table S2: most used c-Met inhibitors as pointed by SelleckChem and AdooQ Biosciences.

Author Contributions: Conceptualization, A.F., V.L., and B.M.; software, E.B. and P.N.; validation, A.F., F.M., and R.D.; formal analysis, E.B., A.F., P.N., and B.M.; investigation, E.B, P.N., V.L., and B.M.; writing-original draft preparation, E.B., A.F., P.N., V.L., and B.M.; writing-review and editing, E.B., A.F., P.N., and B.M.; supervision, F.M., R.D., and B.M. All authors have read and agreed to the published version of the manuscript.

Funding: This research received no external funding.

Acknowledgments: Experiments presented in this paper were carried out using the Grid'5000 testbed, supported by a scientific interest group hosted by Inria and including CNRS, RENATER, and several Universities as well as other organizations (see https: / / www.grid5000.fr). We are much grateful to all members of our labs for helpful discussion and advice.

Conflicts of Interest: The authors declare no conflict of interest.

\section{Abbreviations}

The following abbreviations are used in this manuscript:

DFG aspartate-phenylalanine-glycine

MD Molecular dynamics

RMSD Root mean square deviation

\section{References}

1. Furlan, A.; Kherrouche, Z.; Montagne, R.; Copin, M.C.; Tulasne, D. Thirty Years of Research on Met Receptor to Move a Biomarker from Bench to Bedside. Cancer Res. 2014, 74, 6737-6744. [CrossRef] [PubMed]

2. Zhang, H.; Feng, Q.; Chen, W.D.; Wang, Y.D. HGF/c-MET: A Promising Therapeutic Target in the Digestive System Cancers. Int. J. Mol. Sci. 2018, 19, 3295. [CrossRef] [PubMed]

3. Rashed, W.M. C-MET as a Potential Target Therapy toward Personalized Therapy in Some Pediatric Tumors: An Overview. Crit. Rev. Oncol. 2018, 131, 7-15. [CrossRef] [PubMed]

4. Bahrami, A.; Shahidsales, S.; Khazaei, M.; Ghayour-Mobarhan, M.; Maftouh, M.; Hassanian, S.M.; Avan, A. C-Met as a Potential Target for the Treatment of Gastrointestinal Cancer: Current Status and Future Perspectives. J. Cell. Physiol. 2017, 232, 2657-2673. [CrossRef] [PubMed]

5. Refaat, T.; Donnelly, E.D.; Sachdev, S.; Parimi, V.; El Achy, S.; Dalal, P.; Farouk, M.; Berg, K.N.; Helenowksi, I.; Gross, J.P.; et al. C-Met Overexpression in Cervical Cancer, a Prognostic Factor and a Potential Molecular Therapeutic Target. Am. J. Clin. Oncol. 2017, 40, 590. [CrossRef] [PubMed]

6. Trovato, M.; Campennì, A.; Giovinazzo, S.; Siracusa, M.; Ruggeri, R.M. Hepatocyte Growth Factor/C-Met Axis in Thyroid Cancer: From Diagnostic Biomarker to Therapeutic Target. Biomark. Insights 2017, 12, 1177271917701126. [CrossRef]

7. Wu, P.; Clausen, M.H.; Nielsen, T.E. Allosteric small-molecule kinase inhibitors. Pharmacol. Ther. 2015, 156, 59-68. [CrossRef]

8. Mo, H.N.; Liu, P. Targeting MET in Cancer Therapy. Chronic Dis. Transl. Med. 2017, 3, 148-153. [CrossRef]

9. Li, C.; Wu, J.; Hynes, M.; Dosch, J.; Sarkar, B.; Welling, T.H.; di Magliano, M.P.; Simeone, D.M. C-Met Is a Marker of Pancreatic Cancer Stem Cells and Therapeutic Target. Gastroenterology 2011, 141, 2218-2227. [CrossRef] 
10. Sawada, K.; Radjabi, A.R.; Shinomiya, N.; Kistner, E.; Kenny, H.; Becker, A.R.; Turkyilmaz, M.A.; Salgia, R.; Yamada, S.D.; Woude, G.F.V.; et al. C-Met Overexpression Is a Prognostic Factor in Ovarian Cancer and an Effective Target for Inhibition of Peritoneal Dissemination and Invasion. Cancer Res. 2007, 67, 1670-1679. [CrossRef]

11. Sierra, J.R.; Tsao, M.S. C-MET as a Potential Therapeutic Target and Biomarker in Cancer. Ther. Adv. Med. Oncol. 2011, 3, S21-S35. [CrossRef] [PubMed]

12. Cui, J.J. Targeting Receptor Tyrosine Kinase MET in Cancer: Small Molecule Inhibitors and Clinical Progress. J. Med. Chem. 2014, 57, 4427-4453. [CrossRef] [PubMed]

13. Parikh, P.K.; Ghate, M.D. Recent Advances in the Discovery of Small Molecule C-Met Kinase Inhibitors. Eur. J. Med. Chem. 2018, 143, 1103-1138. [CrossRef] [PubMed]

14. Pasquini, G.; Giaccone, G. C-MET Inhibitors for Advanced Non-Small Cell Lung Cancer. Expert Opin. Investig. Drugs 2018, 27, 363-375. [CrossRef] [PubMed]

15. Yuan, H.; Liu, Q.; Zhang, L.; Hu, S.; Chen, T.; Li, H.; Chen, Y.; Xu, Y.; Lu, T. Discovery, Optimization and Biological Evaluation for Novel c-Met Kinase Inhibitors. Eur. J. Med. Chem. 2018, 143, 491-502. [CrossRef] [PubMed]

16. Zhu, K.; Kong, X.; Zhao, D.; Liang, Z.; Luo, C. C-MET Kinase Inhibitors: A Patent Review (2011-2013). Expert Opin. Ther. Patents 2014, 24, 217-230. [CrossRef] [PubMed]

17. Lv, P.C.; Wang, Z.C.; Zhu, H.L. Recent Advances in the Design and Synthesis of C-Met Inhibitors as Anticancer Agents (2014-Present). Curr. Med. Chem. 2017, 24, 57-64. [CrossRef]

18. Sun, Z.G.; Yang, Y.A.; Zhang, Z.G.; Zhu, H.L. Optimization techniques for novel c-Met kinase inhibitors. Expert Opin. Drug Discov. 2019, 14, 59-69. [CrossRef]

19. Hughes, V.S.; Siemann, D.W. Have Clinical Trials Properly Assessed C-Met Inhibitors? Trends Cancer 2018, 4, 94-97. [CrossRef]

20. Miranda, O.; Farooqui, M.; Siegfried, J. Status of Agents Targeting the HGF/c-Met Axis in Lung Cancer. Cancers 2018, 10, 280. [CrossRef]

21. Cortot, A.B.; Kherrouche, Z.; Descarpentries, C.; Wislez, M.; Baldacci, S.; Furlan, A.; Tulasne, D. Exon 14 deleted MET receptor as a new biomarker and target in cancers. JNCI J. Natl. Cancer Inst. 2017, 109, djw262. [CrossRef] [PubMed]

22. Asses, Y.; Venkatraman, V.; Leroux, V.; Ritchie, D.W.; Maigret, B. Exploring C-Met Kinase Flexibility by Sampling and Clustering Its Conformational Space. Proteins Struct. Funct. Bioinform. 2012, 80, 1227-1238. [CrossRef] [PubMed]

23. Dussault, I.; Bellon, S.F. C-Met Inhibitors with Different Binding Modes: Two Is Better than One. Cell Cycle 2008, 7, 1157-1160. [CrossRef] [PubMed]

24. Jacobs, M.D.; Caron, P.R.; Hare, B.J. Classifying Protein Kinase Structures Guides Use of Ligand-Selectivity Profiles to Predict Inactive Conformations: Structure of Lck/Imatinib Complex. Proteins Struct. Funct. Bioinform. 2008, 70, 1451-1460. [CrossRef]

25. Druker, B.J.; Talpaz, M.; Resta, D.J.; Peng, B.; Buchdunger, E.; Ford, J.M.; Lydon, N.B.; Kantarjian, H.; Capdeville, R.; Ohno-Jones, S.; et al. Efficacy and Safety of a Specific Inhibitor of the BCR-ABL Tyrosine Kinase in Chronic Myeloid Leukemia. N. Engl. J. Med. 2001, 344, 1031-1037. [CrossRef]

26. Capdeville, R.; Buchdunger, E.; Zimmermann, J.; Matter, A. Glivec (STI571, Imatinib), a Rationally Developed, Targeted Anticancer Drug. Nat. Rev. Drug Discov. 2002, 1, 493. [CrossRef]

27. Aliebrahimi, S.; Kouhsari, S.M.; Ostad, S.N.; Arab, S.S.; Karami, L. Identification of Phytochemicals Targeting C-Met Kinase Domain Using Consensus Docking and Molecular Dynamics Simulation Studies. Cell Biochem. Biophys. 2018, 76, 135-145. [CrossRef]

28. Li, M.J.; Wu, G.Z.; Kaas, Q.; Jiang, T.; Yu, R.L. Development of Efficient Docking Strategies and Structure-Activity Relationship Study of the c-Met Type II Inhibitors. J. Mol. Graph. Model. 2017, 75, 241-249. [CrossRef]

29. Amaro, R.E.; Baudry, J.; Chodera, J.; Demir, O.; McCammon, J.A.; Miao, Y.; Smith, J.C. Ensemble Docking in Drug Discovery. Biophys. J. 2018, 114, 2271-2278. [CrossRef]

30. Patané, S.; Pietrancosta, N.; Hassani, H.; Leroux, V.; Maigret, B.; Kraus, J.L.; Dono, R.; Maina, F. A New Met Inhibitory-Scaffold Identified by a Focused Forward Chemical Biological Screen. Biochem. Biophys. Res. Commun. 2008, 375, 184-189. [CrossRef] 
31. Furlan, A.; Colombo, F.; Kover, A.; Issaly, N.; Tintori, C.; Angeli, L.; Leroux, V.; Letard, S.; Amat, M.; Asses, Y.; et al. Identification of New Aminoacid Amides Containing the Imidazo [2, 1-b] Benzothiazol-2-Ylphenyl Moiety as Inhibitors of Tumorigenesis by Oncogenic Met Signaling. Eur. J. Med. Chem. 2012, 47, 239-254. [CrossRef] [PubMed]

32. Asses, Y.; Leroux, V.; Tairi-Kellou, S.; Dono, R.; Maina, F.; Maigret, B. Analysis of C-Met Kinase Domain Complexes: A New Specific Catalytic Site Receptor Model for Defining Binding Modes of ATP-Competitive Ligands. Chem. Biol. Drug Des. 2009, 74, 560-570. [CrossRef] [PubMed]

33. Gimeno, A.; Ojeda-Montes, M.; Tomás-Hernández, S.; Cereto-Massagué, A.; Beltrán-Debón, R.; Mulero, M.; Pujadas, G.; Garcia-Vallvé, S. The Light and Dark Sides of Virtual Screening: What Is There to Know? Int. J. Mol. Sci. 2019, 20, 1375. [CrossRef] [PubMed]

34. Kioshima, E.S.; Shinobu-Mesquita, C.S.; Abadio, A.K.R.; Felipe, M.S.S.; Svidzinski, T.I.E.; Maigret, B. Selection of potential anti-adhesion drugs by in silico approaches targeted to ALS3 from Candida albicans. Biotechnol. Lett. 2019, 41, 1391-1401. [CrossRef]

35. Bresso, E.; Fernandez, D.; Amora, D.X.; Noel, P.; Petitot, A.S.; de Sa, M.E.L.; Albuquerque, E.V.S.; Danchin, E.G.J.; Maigret, B.; Martins, N.F. A Chemosensory GPCR as a Potential Target to Control the Root-Knot Nematode Meloidogyne incognita Parasitism in Plants. Molecules 2019, 24, 3798. [CrossRef]

36. Rodrigues-Vendramini, F.A.V.; Faria, D.R.; Arita, G.S.; Capoci, I.R.G.; Sakita, K.M.; Caparroz-Assef, S.M.; Becker, T.C.A.; de Souza Bonfim-Mendonça, P.; Felipe, M.S.; Svidzinski, T.I.E.; et al. Antifungal activity of two oxadiazole compounds for the paracoccidioidomycosis treatment. PLoS Negl. Trop. Dis. 2019, 13, e0007441. [CrossRef]

37. Gilad, Y.; Nadassy, K.; Senderowitz, H. A Reliable Computational Workflow for the Selection of Optimal Screening Libraries. J. Cheminform. 2015, 7, 61. [CrossRef]

38. Petrone, P.M.; Wassermann, A.M.; Lounkine, E.; Kutchukian, P.; Simms, B.; Jenkins, J.; Selzer, P.; Glick, M. Biodiversity of Small Molecules-a New Perspective in Screening Set Selection. Drug Discov. Today 2013, 18, 674-680. [CrossRef]

39. Huggins, D.J.; Venkitaraman, A.R.; Spring, D.R. Rational Methods for the Selection of Diverse Screening Compounds. ACS Chem. Biol. 2011, 6, 208-217. [CrossRef]

40. Ma, C.; Lazo, J.S.; Xie, X.Q. Compound Acquisition and Prioritization Algorithm for Constructing Structurally Diverse Compound Libraries. ACS Comb. Sci. 2011, 13, 223-231. [CrossRef]

41. Xi, H.; Lunney, E.A. The Design, Annotation, and Application of a Kinase-Targeted Library. In Chemical Library Design; Humana Press: Totowa, NJ, USA, 2011; pp. 279-291.

42. Deanda, F.; Stewart, E.L.; Reno, M.J.; Drewry, D.H. Kinase-Targeted Library Design through the Application of the PharmPrint Methodology. J. Chem. Inf. Model. 2008, 48, 2395-2403. [CrossRef] [PubMed]

43. Dutta, S.; Mahalanobish, S.; Saha, S.; Ghosh, S.; Sil, P.C. Natural Products: An Upcoming Therapeutic Approach to Cancer. Food Chem. Toxicol. 2019, 128, 240-255. [CrossRef] [PubMed]

44. Henkin, J.M.; Ren, Y.; Soejarto, D.D.; Kinghorn, A.D. The Search for Anticancer Agents from Tropical Plants. In Progress in the Chemistry of Organic Natural Products 107; Springer: New York, NY, USA, 2018; pp. 1-94.

45. Mondal, S.; Bandyopadhyay, S.; K Ghosh, M.; Mukhopadhyay, S.; Roy, S.; Mandal, C. Natural Products: Promising Resources for Cancer Drug Discovery. Anti-Cancer Agents Med. Chem. (Former Curr. Med.-Chem.-Anti-Cancer Agents) 2012, 12, 49-75. [CrossRef]

46. Nowak-Sliwinska, P.; Scapozza, L.; i Altaba, A.R. Drug Repurposing in Oncology: Compounds, Pathways, Phenotypes and Computational Approaches for Colorectal Cancer. Biochim. Biophys. Acta (BBA) Rev. Cancer 2019, 1871, 434-454. [CrossRef] [PubMed]

47. Cheng, F. In Silico Oncology Drug Repositioning and Polypharmacology. In Cancer Bioinformatics; Springer: New York, NY, USA, 2019; pp. 243-261.

48. Abdelaleem, M.; Ezzat, H.; Osama, M.; Megahed, A.; Alaa, W.; Gaber, A.; Shafei, A.; Refaat, A. Prospects for Repurposing CNS Drugs for Cancer Treatment. Oncol. Rev. 2019, 13, 411. [CrossRef] [PubMed]

49. Yadav, V.; Talwar, P. Repositioning of Fluoroquinolones from Antibiotic to Anti-Cancer Agents: An Underestimated Truth. Biomed. Pharmacother. 2019, 111, 934-946. [CrossRef]

50. Lipinski, C.A. Lead-and Drug-like Compounds: The Rule-of-Five Revolution. Drug Discov. Today Technol. 2004, 1, 337-341. [CrossRef] 
51. Evangelista Falcon, W.; Ellingson, S.R.; Smith, J.C.; Baudry, J. Ensemble Docking in Drug Discovery: How Many Protein Configurations from Molecular Dynamics Simulations are Needed To Reproduce Known Ligand Binding? J. Phys. Chem. B 2019, 123, 5189-5195. [CrossRef]

52. Motta, S.; Bonati, L. Modeling Binding with Large Conformational Changes: Key Points in Ensemble-Docking Approaches. J. Chem. Inf. Model. 2017, 57, 1563-1578. [CrossRef]

53. Berman, H.M. The Protein Data Bank. Nucleic Acids Res. 2000, 28, 235-242. [CrossRef]

54. Rahman, R.; Ung, P.M.U.; Schlessinger, A. KinaMetrix: A web resource to investigate kinase conformations and inhibitor space. Nucleic Acids Res. 2019, 47, D361-D366. [CrossRef] [PubMed]

55. Holm, L.; Laakso, L.M. Dali server update. Nucleic Acids Res. 2016, 44, W351-W355. [CrossRef] [PubMed]

56. Ibrahim, H.S.; Albakri, M.E.; Mahmoud, W.R.; Allam, H.A.; Reda, A.M.; Abdel-Aziz, H.A. Synthesis and Biological Evaluation of Some Novel Thiobenzimidazole Derivatives as Anti-Renal Cancer Agents through Inhibition of c-MET Kinase. Bioorg. Chem. 2019, 85, 337-348. [CrossRef] [PubMed]

57. Phillips, J.C.; Braun, R.; Wang, W.; Gumbart, J.; Tajkhorshid, E.; Villa, E.; Chipot, C.; Skeel, R.D.; Kalé, L.; Schulten, K. Scalable Molecular Dynamics with NAMD. J. Comput. Chem. 2005, 26, 1781-1802. [CrossRef]

58. Jones, G.; Willett, P.; Glen, R.C.; Leach, A.R.; Taylor, R. Development and validation of a genetic algorithm for flexible docking 1 1Edited by F. E. Cohen. J. Mol. Biol. 1997, 267, 727-748. [CrossRef]

59. Hendlich, M.; Rippmann, F.; Barnickel, G. LIGSITE: Automatic and Efficient Detection of Potential Small Molecule-Binding Sites in Proteins. J. Mol. Graph. Model. 1997, 15, 359-363. [CrossRef]

60. Bolze, R.; Cappello, F.; Caron, E.; Daydé, M.; Desprez, F.; Jeannot, E.; Jégou, Y.; Lanteri, S.; Leduc, J.; Melab, N.; et al. Grid'5000: A Large Scale and Highly Reconfigurable Experimental Grid Testbed. Int. J. High Perform. Comput. Appl. 2006, 20, 481-494. [CrossRef]

61. Ghemtio, L.; Jeannot, E.; Maigret, B. Efficiency of a Hierarchical Protocol for High Throughput Structure-Based Virtual Screening on GRID5000 Cluster Grid. Open Access Bioinform. 2010, 2, 41-53.

62. Furlan, A.; Roux, B.; Lamballe, F.; Conti, F.; Issaly, N.; Daian, F.; Guillemot, J.F.; Richelme, S.; Contensin, M.; Bosch, J.; et al. Combined Drug Action of 2-Phenylimidazo [2, 1-b] Benzothiazole Derivatives on Cancer Cells According to Their Oncogenic Molecular Signatures. PLoS ONE 2012, 7, e46738. [CrossRef]

63. Salentin, S.; Schreiber, S.; Haupt, V.J.; Adasme, M.F.; Schroeder, M. PLIP: Fully Automated Protein-Ligand Interaction Profiler. Nucleic Acids Res. 2015, 43, W443-W447. [CrossRef]

64. Colombo, F.; Tintori, C.; Furlan, A.; Borrelli, S.; Christodoulou, M.S.; Dono, R.; Maina, F.; Botta, M.; Amat, M.; Bosch, J.; et al. 'Click' synthesis of a triazole-based inhibitor of Met functions in cancer cells. Bioorg. Med. Chem. Lett. 2012, 22, 4693-4696. [CrossRef] [PubMed]

65. Roskoski, R. Classification of small molecule protein kinase inhibitors based upon the structures of their drug-enzyme complexes. Pharmacol. Res. 2016, 103, 26-48. [CrossRef] [PubMed]

66. Zhao, Z.; Xie, L.; Bourne, P.E. Structural Insights into Characterizing Binding Sites in Epidermal Growth Factor Receptor Kinase Mutants. J. Chem. Inf. Model. 2019, 59, 453-462. [CrossRef] [PubMed]

67. Panicker, R.C.; Chattopadhaya, S.; Coyne, A.G.; Srinivasan, R. Allosteric Small-Molecule Serine/Threonine Kinase Inhibitors. In Protein Allostery in Drug Discovery; Springer: Singapore, 2019; Volume 1163, pp. $253-278$.

68. Dong, J.; Cao, D.S.; Miao, H.Y.; Liu, S.; Deng, B.C.; Yun, Y.H.; Wang, N.N.; Lu, A.P.; Zeng, W.B.; Chen, A.F. ChemDes: An integrated web-based platform for molecular descriptor and fingerprint computation. J. Cheminform. 2015, 7, 60. [CrossRef] [PubMed]

69. Kim, S.; Thiessen, P.A.; Bolton, E.E.; Chen, J.; Fu, G.; Gindulyte, A.; Han, L.; He, J.; He, S.; Shoemaker, B.A.; et al. PubChem Substance and Compound databases. Nucleic Acids Res. 2016, 44, D1202-D1213. [CrossRef] [PubMed]

70. MDDR. Available online: www.3dsbiovia.com/products/collaborative-science/databases/bioactivitydatabases/mddr.html (accessed on 18 February 2020).

71. Selleckchem.Com-Inhibitor Expert. Available online: www.selleckchem.com (accessed on 18 February 2020).

72. Mohareb, R.M.; Hilmy, K.M.; Elshehawy, Y.A. Discovery of new thiophene, pyrazole, isoxazole derivatives as antitumor, c-Met, tyrosine kinase and Pim-1 kinase inhibitors. Bull. Chem. Soc. Ethiop. 2018, 32, 285. [CrossRef]

73. Shi, L.; Wu, T.T.; Wang, Z.; Xue, J.Y.; Xu, Y.G. Discovery of quinazolin-4-amines bearing benzimidazole fragments as dual inhibitors of c-Met and VEGFR-2. Bioorg. Med. Chem. 2014, 22, 4735-4744. [CrossRef]

74. Fancelli, D.; Pevarello, P.; Varasi, M. Thiophene Derivatives Active as Kinase Inhibitors, Process for Their Preparation and Pharmaceutical Compositions Comprising Them. WO2001EP06763, 14 June 2001. 
75. Zhan, W.; Che, J.; Xu, L.; Wu, Y.; Hu, X.; Zhou, Y.; Cheng, G.; Hu, Y.; Dong, X.; Li, J. Discovery of pyrazole-thiophene derivatives as highly Potent, orally active Akt inhibitors. Eur. J. Med. Chem. 2019, 180, 72-85. [CrossRef]

76. Zhang, S.; Song, Q.; Wang, X.; Wei, Z.; Yu, R.; Wang, X.; Jiang, T. Virtual Screening Guided Design, Synthesis and Bioactivity Study of Benzisoselenazolones (BISAs) on Inhibition of c-Met and Its Downstream Signalling Pathways. Int. J. Mol. Sci. 2019, 20, 2489. [CrossRef]

77. Balasubramanian, P.K.; Balupuri, A.; Bhujbal, S.P.; Cho, S.J. 3D-QSAR-Aided Design of Potent c-Met Inhibitors Using Molecular Dynamics Simulation and Binding Free Energy Calculation. J. Biomol. Struct. Dyn. 2019, 37, 2165-2178. [CrossRef]

78. Zhang, Q.W.; Ye, Z.D.; Shen, C.; Tie, H.X.; Wang, L.; Shi, L. Synthesis of Novel 6, 7-Dimethoxy-4-Anilinoquinolines as Potent c-Met Inhibitors. J. Enzym. Inhib. Med. Chem. 2019, 34, 124-133. [CrossRef] [PubMed]

79. Singh, P.K.; Silakari, O. Molecular Dynamics Guided Development of Indole Based Dual Inhibitors of EGFR (T790M) and c-MET. Bioorg. Chem. 2018, 79, 163-170. [CrossRef] [PubMed]

80. Yan, M.; Wang, H.; Wang, Q.; Zhang, Z.; Zhang, C. Allosteric inhibition of c-Met kinase in sub-microsecond molecular dynamics simulations induced by its inhibitor, tivantinib. Phys. Chem. Chem. Phys. 2016, 18, 10367-10374. [CrossRef] [PubMed]

81. Modi, V.; Dunbrack, R.L. Defining a new nomenclature for the structures of active and inactive kinases. Proc. Natl. Acad. Sci. USA 2019, 116, 6818-6827. [CrossRef] [PubMed]

82. Mashayekh, K.; Sharifi, S.; Damghani, T.; Elyasi, M.; Avestan, M.S.; Pirhadi, S. Clustering and Sampling of the c-Met Conformational Space: A Computational Drug Discovery Study. Comb. Chem. High Throughput Screen. 2020, 22, 635-648. [CrossRef]

(C) 2020 by the authors. Licensee MDPI, Basel, Switzerland. This article is an open access article distributed under the terms and conditions of the Creative Commons Attribution (CC BY) license (http://creativecommons.org/licenses/by/4.0/). 